\title{
Improved clinical outcomes of patients with ovarian carcinoma arising in endometriosis
}

\author{
Jiaqi Lu', ${ }^{1, *}$ Xiang Tao $^{3, *}$, Jiayi Zhou ${ }^{2}$, Yingying Lu${ }^{1}$, Zehua Wang ${ }^{2}$, Haiou Liu ${ }^{2}$ and \\ Congjian $X \mathbf{u}^{1,2}$ \\ ${ }^{1}$ Department of Gynaecology, Obstetrics and Gynecology Hospital, Fudan University, Shanghai, China \\ 2 Shanghai Key Laboratory of Female Reproductive Endocrine Related Diseases, Obstetrics and Gynecology Hospital, Fudan \\ University, Shanghai, China \\ ${ }^{3}$ Department of Pathology, Obstetrics and Gynecology Hospital, Fudan University, Shanghai, China \\ * These authors have contributed equally to this work \\ Correspondence to: Haiou Liu, email: liuhaiou@fudan.edu.cn \\ Congjian XU, email: xucongjian@gmail.com
}

Keywords: ovarian cancer, endometriosis, overall survival, progression-free survival, prognostic marker

Received: May 30, $2016 \quad$ Accepted: December 12, $2016 \quad$ Published: December 15, 2016

\section{ABSTRACT}

Background: Despite enormous efforts to dissect the role of endometriosis in ovarian cancer development, the difference in prognosis between ovarian cancer patients with or without endometriosis remains elusive. The purpose of this study is to assess the association between endometriosis and the prognosis in patients with ovarian cancer.

Results: Ovarian cancer arising in endometriosis tended to be presented as clear cell histology, early stage, less intraperitoneal metastasis and ascites, and lower CA125 level compared with those without endometriosis. Multivariate Cox regression analysis identified endometriosis as an independent prognostic factor for progression free survival $(P=0.002)$ and overall survival $(P=0.009)$ in all patients and especially for early stage. A nomogram integrating endometriosis, FIGO stage and CA125 was established to predict progression free survival and overall survival.

Materials and methods: This study retrospectively enrolled 196 ovarian cancers arising or not in endometriosis judged by adjunctive use of CD10 immunohistochemistry in conjunction with H\&E staining specimens. Clinicopathologic variables, progression-free survival (PFS) and overall survival (OS) were recorded. Kaplan-Meier analysis was performed to compare survival curves. Cox regression models were used to analyze the effect of endometriosis on PFS and OS. A prognostic nomogram was constructed based on the independent prognostic factors identified by multivariate analysis.

Conclusions: Endometriosis is an independent predictor of prognosis in ovarian cancer patients.

\section{INTRODUCTION}

Endometriosis, a chronic gynecological disease, shares common characteristics with malignant cells [1]. Although endometriosis remains largely benign, malignant transformation may account for up to $1 \%$ of cases, most commonly from ovarian lesions $[2,3]$. In addition to epidemiological evidence between endometriosis and ovarian cancer, the pathological findings confirmed endometriosis in close proximity to the tumor $[4,5]$. Both ovarian clear cell and endometrioid carcinoma are associated with endometriosis [6].

The difference in prognosis between ovarian cancer patients with and without endometriosis remains elusive. Previous studies reported that ovarian cancer patients with endometriosis are associated with better prognosis 
compared with those without concomitant endometriosis [7-10]. However, other studies have not confirmed these findings after adjusting for potential confounding factors [11]. Resolving this issue is difficult because the criteria for the diagnosis of endometriosis associated ovarian cancer (EAOC) is heterogenous. Given these conflicting findings, we sought to characterize ovarian cancers arising from endometriosis based on pathological identification and to evaluate the prognostic impact of the endometriosis on ovarian cancer patients for risk stratification.

\section{RESULTS}

\section{Patient characteristics and associations with endometriosis}

A total of 196 patients met the inclusion criteria, of which $58(30.0 \%)$ cases have been affected by tumors arising in endometriosis, while 138 (70.0\%) had no concomitant endometriosis. Of the 58 specimens were histologically positive for ovarian cancer arising in endometriosis by $\mathrm{H} \& \mathrm{E}$ staining, reconfirmation of all samples by CD10 staining. CD10 IHC result was positive in each endometriosis specimens judged by H\&E staining (Figure 1). CD10 staining was confined to endometrial stromal cells, and generally moderate to strong (Supplementary Table 1). Patients and tumor characteristics of the two groups are presented in Table 1. Forty-eight patients $(82.76 \%)$ were clear cell histology type arising from endometriosis compared with $65.94 \%$ of clear cell ovarian cancer without endometriosis $(P=$ $0.048)$. Fifty-one patients $(87.93 \%)$ with endometriosis were diagnosed at the FIGO stage (I-II) compared with $66.67 \%$ of patients without endometriosis $(P=0.004)$. Intraperitoneal metastasis was detected in 41 patients $(29.71 \%)$ in the endometriosis-free group, compared to 8 $(13.79 \%)$ patients with endometriosis group $(P=0.03)$. Twenty-one patients $(15.22 \%)$ without endometriosis tend to have more ascites compared to 1 case $(1.42 \%)$ arising in endometriosis $(P=0.013)$. Eighty-three patients $(60.14 \%)$ without endometriosis present high CA125 level, compared to 25 patients $(43.1 \%)$ arising in endometriosis $(P=0.042)$. No association between endometriosis and other clinicopathologic characteristics was observed.

\section{Endometriosis is associated with PFS and OS in ovarian cancer patients}

To further estimate the relationship between endometriosis and clinical outcomes of ovarian cancer patients, we applied Kaplan-Meier survival analysis and log-rank test to compare PFS and OS between two groups. As shown in Figure 2, patients with endometriosis were significantly associated with late recurrence $(P<$


Figure 1: Representative photographs of ovarian clear cell carcinoma arising in endometriosis. A.-C. H\&E staining of ovarian clear cell carcinoma arising in endometriosis. D.-F. Weak, moderate and strong immunohistochemical staining with CD10 of stroma in ovarian clear cell carcinoma specimen. Bar $=100 \mu \mathrm{m}$. 
Table 1: Patient characteristics in ovarian cancer arising or not from endometriosis.

\begin{tabular}{|c|c|c|c|}
\hline \multirow{2}{*}{ Characteristic } & \multicolumn{2}{|c|}{ Endometriosis } & \multirow{2}{*}{$P$ value } \\
\hline & No $(n=138)$ & Arising $(n=58)$ & \\
\hline Age (years) & $51.08(49.45-52.71)$ & $49.64(47.62-51.65)$ & 0.314 \\
\hline $\begin{array}{l}\text { Histology } \\
\text { Clear cell } \\
\text { Endometrioid } \\
\text { Mixed } \\
\end{array}$ & $\begin{array}{l}91(65.94 \%) \\
37(26.81 \%) \\
10(7.25 \%) \\
\end{array}$ & $\begin{array}{l}48(82.76 \%) \\
9(15.52 \%) \\
1(1.72 \%) \\
\end{array}$ & 0.048 \\
\hline $\begin{array}{l}\text { Ovarian involvement } \\
\text { Monolateral } \\
\text { Bilateral } \\
\end{array}$ & $\begin{array}{c}108(78.26 \%) \\
30(21.74 \%)\end{array}$ & $\begin{array}{c}52(89.66 \%) \\
6(10.34 \%) \\
\end{array}$ & 0.060 \\
\hline $\begin{array}{l}\text { ECOG performance status } \\
0-1 \\
2-3 \\
\end{array}$ & $\begin{array}{l}128(92.75 \%) \\
10(7.25 \%) \\
\end{array}$ & $\begin{array}{l}55(94.83 \%) \\
3(5.17 \%) \\
\end{array}$ & 0.827 \\
\hline $\begin{array}{l}\text { FIGO stage } \\
\text { I } \\
\text { II } \\
\text { III } \\
\text { IV }\end{array}$ & $\begin{array}{l}75(54.35 \%) \\
17(12.32 \%) \\
40(28.99 \%) \\
6(4.35 \%)\end{array}$ & $\begin{array}{l}46(79.31 \%) \\
5(8.62 \%) \\
7(12.07 \%) \\
0(0.00 \%)\end{array}$ & $<0.001$ \\
\hline $\begin{array}{l}\text { FIGO stage } \\
\text { Early stage }(\mathrm{I} / \mathrm{II}) \\
\text { Late stage }(\mathrm{III} / \mathrm{IV}) \\
\end{array}$ & $\begin{array}{l}92(66.67 \%) \\
46(33.33 \%)\end{array}$ & $\begin{array}{c}51(87.93 \%) \\
7(12.07 \%) \\
\end{array}$ & 0.004 \\
\hline $\begin{array}{l}\text { Lymph node metastasis } \\
\text { negative } \\
\text { positive }\end{array}$ & $\begin{array}{c}121(87.68 \%) \\
17(12.32 \%) \\
\end{array}$ & $\begin{array}{l}54(93.10 \%) \\
4(6.90 \%) \\
\end{array}$ & 0.386 \\
\hline $\begin{array}{l}\text { Intraperitoneal metastasis } \\
\text { negative } \\
\text { positive }\end{array}$ & $\begin{array}{l}97(70.29 \%) \\
41(29.71 \%) \\
\end{array}$ & $\begin{array}{c}50(86.21 \%) \\
8(13.79 \%) \\
\end{array}$ & 0.030 \\
\hline $\begin{array}{l}\text { Residual tumor }(\mathrm{cm}) \\
\leq 1 \\
>1\end{array}$ & $\begin{array}{c}121(87.68 \%) \\
17(12.32 \%) \\
\end{array}$ & $\begin{array}{l}54(93.10 \%) \\
4(6.90 \%) \\
\end{array}$ & 0.386 \\
\hline $\begin{array}{l}\text { Preoperative ascites }(\mathrm{ml}) \\
<500 \\
\geq 500\end{array}$ & $\begin{array}{c}117(84.78 \%) \\
21(15.22 \%)\end{array}$ & $\begin{array}{l}57(98.28 \%) \\
1(1.42 \%) \\
\end{array}$ & 0.013 \\
\hline $\begin{array}{l}\text { Preoperative CA125 level (U/ml) } \\
<35 \\
\geq 35\end{array}$ & $\begin{array}{l}55(39.86 \%) \\
83(60.14 \%)\end{array}$ & $\begin{array}{l}33(56.90 \%) \\
25(43.10 \%)\end{array}$ & 0.042 \\
\hline
\end{tabular}

Abbreviations: ECOG, Eastern Cooperative Oncology Group; FIGO, International federation of gynecology and obstetrics; CA125, cancer antigen 125. All data presented as median $(95 \% \mathrm{CI})$ or number. Bold values indicate $P<0.05$.

$0.001)$ and better OS $(P<0.001)$. We further performed a subgroup analysis by FIGO stage (Figure 3). The prognostic value of endometriosis is more prominent in patients with early stage (FIGO I-II) $(P<0.001$ for both PFS and OS).

\section{Endometriosis is an independent predictor of PFS and $\mathrm{OS}$}

To determine the prognostic significance of clinicopathologic variables of PFS and OS, we performed univariate Cox analysis. As present in Table 2 , endometriosis was identified as a protective factor that might affect PFS (hazard ratio (HR) 0.187, $P<$ $0.001)$ and OS (HR $0.238, P<0.001$ ) of ovarian cancer patients. In addition, FIGO stage, lymph node metastasis, intraperitoneal metastasis, residual tumor, ascites, and
CA125 were identified as unfavorable factor for PFS and OS. On multivariate analysis, endometriosis is an independent prognostic factor for PFS (HR 0.284, $P=$ 0.002 ) and $\mathrm{OS}$ (HR 0.349, $P=0.009$ ).

\section{Association between endometriosis and clinical outcomes in early stage patients}

To evaluate the clinical usefulness of endometriosis in early stage ovarian cancer, we performed subgroup analysis upon early stage patients. By univariate analysis, intraperitoneal metastasis $(P<0.001$ for both PFS and OS) and residual tumor $(P=0.027, P=0.021$ for PFS and $\mathrm{OS}$, respectively) were significantly associated with poor clinical outcomes, while endometriosis $(P=0.004$, $P=0.007$ for PFS and OS, respectively) was significantly associated with better prognosis (Table 3). Multivariate 
A

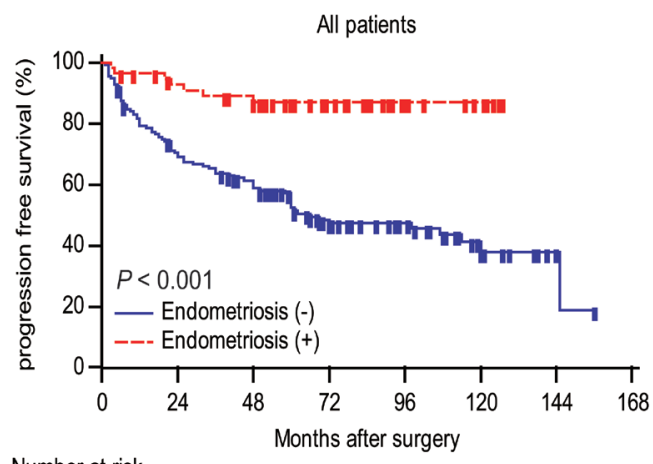

Number at risk

$\begin{array}{llllllll}138 & 92 & 72 & 42 & 31 & 11 & 2 & 0 \\ 58 & 50 & 44 & 30 & 15 & 10 & 0 & 0\end{array}$

B

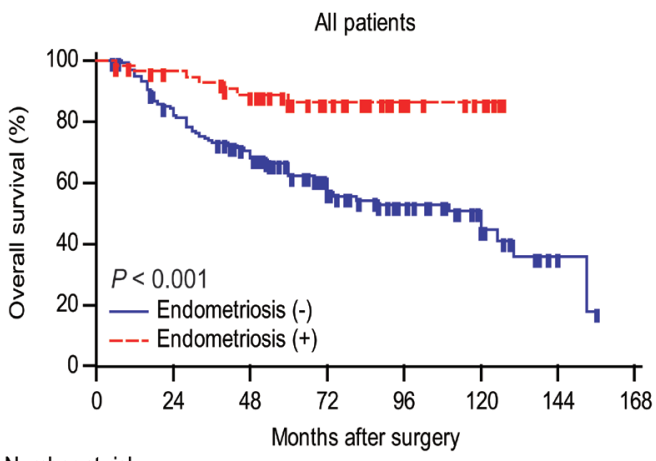

Number at risk

$\begin{array}{llllllll}138 & 109 & 82 & 49 & 33 & 13 & 2 & 0 \\ 58 & 52 & 45 & 30 & 15 & 10 & 0 & 0\end{array}$

Figure 2: Analyses of progression-free survival and overall survival according to endometriosis in all patients. A.KaplanMeier curves for PFS of ovarian cancer patients categorized by endometriosis. Patients who were lost to follow-up or who showed no progression at the time of the last follow-up were censored (+). B. Kaplan-Meier curves for OS of ovarian cancer patients categorized by endometriosis. Patients who were lost to follow-up or who were still alive at the time of the last follow-up were censored $(+)$. $P$ values were calculated by log-rank test.

A

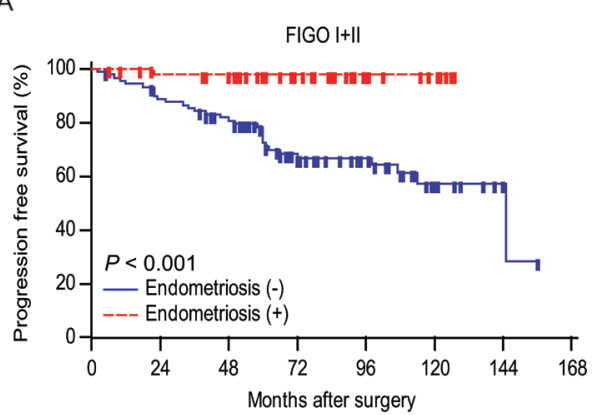

Number at risk

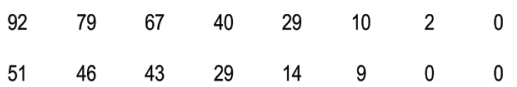

C

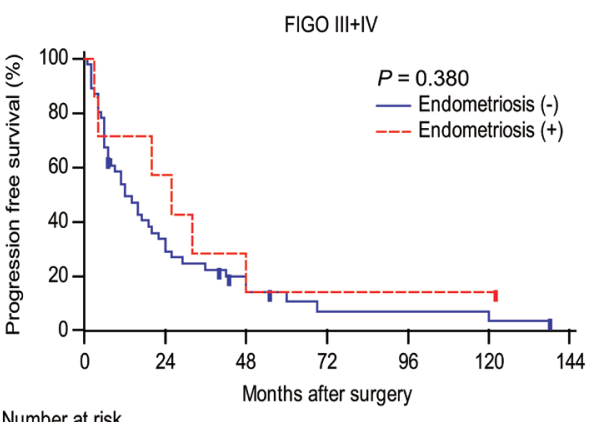

$46-13 \quad 5 \quad 2 \quad 2=1-0$

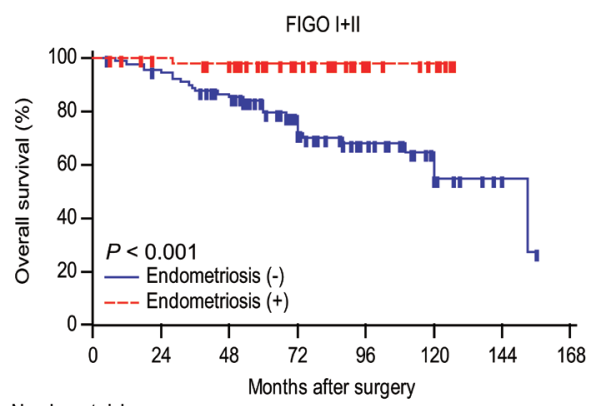

Number at risk

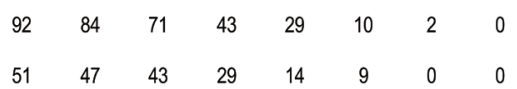

D

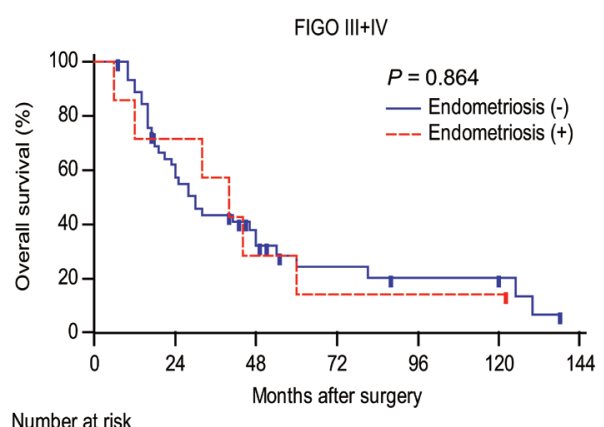

Number at risk

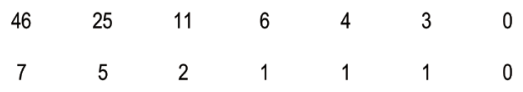

Figure 3: Analyses of progression-free survival and overall survival according to endometriosis in different FIGO stage groups. A., C. Kaplan-Meier curves for PFS of ovarian cancer patients categorized by endometriosis in FIGO stage I+II and III+IV, respectively. Patients who were lost to follow-up or who showed no progression at the time of the last follow-up were censored (+). B., D. Kaplan-Meier curves for OS of ovarian cancer patients categorized by endometriosis in FIGO stage I+II and III+IV, respectively. Patients who were lost to follow-up or who were still alive at the time of the last follow-up were censored $(+) . P$ values were calculated by log-rank test. 
Table 2: Univariate and multivariate Cox regression analysis for progression-free survival (PFS) and overall survival (OS) of ovarian cancer patients according to various clinic-pathologic factors $(n=196)$.

\begin{tabular}{|c|c|c|c|c|}
\hline \multirow{2}{*}{ Clinical variables } & \multicolumn{2}{|l|}{ PFS } & \multicolumn{2}{|l|}{ OS } \\
\hline & HR $(95 \%$ CI) & $P$ value & HR $(95 \%$ CI $)$ & $P$ value \\
\hline \multicolumn{5}{|l|}{ Univariate analysis } \\
\hline Age & $0.999(0.975-1.023)$ & 0.915 & $1.003(0.977-1.030)$ & 0.814 \\
\hline $\begin{array}{l}\text { Histology } \\
\text { clear cell } \\
\text { Endometrioid } \\
\text { Mixed }\end{array}$ & $\begin{array}{c}\text { Reference } \\
0.967(0.585-1.671) \\
1.896(0.903-3.982)\end{array}$ & 0.286 & $\begin{array}{c}\text { Reference } \\
0.910(0.514-1.611) \\
1.845(0.867-3.926)\end{array}$ & 0.282 \\
\hline $\begin{array}{l}\text { ECOG performance } \\
0-1 \\
2-3\end{array}$ & $\begin{array}{c}\text { Reference } \\
1.895(0.913-3.932)\end{array}$ & 0.088 & $\begin{array}{c}\text { Reference } \\
1.567(0.678-3.621)\end{array}$ & 0.296 \\
\hline $\begin{array}{l}\text { FIGO stage } \\
\text { Early stage (I-II) } \\
\text { Late stage (III-IV) }\end{array}$ & $\begin{array}{c}\text { Reference } \\
10.367(6.460-16.638)\end{array}$ & $<0.001$ & $\begin{array}{c}\text { Reference } \\
7.413(4.526-12.139)\end{array}$ & $<0.001$ \\
\hline $\begin{array}{l}\text { Lymph node metastasis } \\
\text { negative } \\
\text { positive }\end{array}$ & $\begin{array}{c}\text { Reference } \\
4.707(2.786-7.952)\end{array}$ & $<0.001$ & $\begin{array}{c}\text { Reference } \\
3.048(1.684-5.517)\end{array}$ & $<0.001$ \\
\hline $\begin{array}{l}\text { Intraperitoneal metastasis } \\
\text { negative } \\
\text { positive }\end{array}$ & $\begin{array}{c}\text { Reference } \\
6.182(3.908-9.778)\end{array}$ & $<0.001$ & $\begin{array}{c}\text { Reference } \\
5.194(3.213-8.398)\end{array}$ & $<0.001$ \\
\hline $\begin{array}{l}\text { Residual tumor }(\mathrm{cm}) \\
\leq 1 \\
>1\end{array}$ & $\begin{array}{c}\text { Reference } \\
5.639(3.375-9.423)\end{array}$ & $<0.001$ & $\begin{array}{c}\text { Reference } \\
4.556(2.651-7.831)\end{array}$ & $<0.001$ \\
\hline $\begin{array}{l}\text { Preoperative ascites }(\mathrm{ml}) \\
<500 \\
\geq 500\end{array}$ & $\begin{array}{c}\text { Reference } \\
2.914(1.682-5.047)\end{array}$ & $<0.001$ & $\begin{array}{c}\text { Reference } \\
2.653(1.473-4.779)\end{array}$ & 0.001 \\
\hline $\begin{array}{l}\text { Preoperative CA125 (U/ml) } \\
<35 \\
\geq 35\end{array}$ & $\begin{array}{c}\text { Reference } \\
2.524(1.561-4.079)\end{array}$ & $<0.001$ & $\begin{array}{c}\text { Reference } \\
2.570(1.536-4.301)\end{array}$ & $<0.001$ \\
\hline $\begin{array}{l}\text { Endometriosis } \\
\text { negative } \\
\text { positive }\end{array}$ & $\begin{array}{c}\text { Reference } \\
0.187(0.086-0.405)\end{array}$ & $<0.001$ & $\begin{array}{c}\text { Reference } \\
0.238(0.109-0.518)\end{array}$ & $<0.001$ \\
\hline \multicolumn{5}{|l|}{ Multivariate analysis } \\
\hline $\begin{array}{l}\text { FIGO stage } \\
\text { Early stage (I-II) } \\
\text { Late stage (III-IV) } \\
\end{array}$ & $\begin{array}{c}\text { Reference } \\
8.642(5.339-13.988) \\
\end{array}$ & $<0.001$ & $\begin{array}{c}\text { Reference } \\
6.158(3.732-10.163) \\
\end{array}$ & $<0.001$ \\
\hline $\begin{array}{l}\text { Preoperative CA125 (U/ml) } \\
<35 \\
\geq 35\end{array}$ & $\begin{array}{c}\text { Reference } \\
2.033(1.249-3.309) \\
\end{array}$ & 0.003 & $\begin{array}{c}\text { Reference } \\
2.150(1.275-3.626)\end{array}$ & 0.010 \\
\hline $\begin{array}{l}\text { Endometriosis } \\
\text { negative } \\
\text { positive }\end{array}$ & $\begin{array}{c}\text { Reference } \\
0.284(0.130-0.623)\end{array}$ & 0.002 & $\begin{array}{c}\text { Reference } \\
0.349(0.159-0.765)\end{array}$ & 0.009 \\
\hline
\end{tabular}

Abbreviations: ECOG, Eastern Cooperative Oncology Group; FIGO, International federation of gynecology and obstetrics; CA125, cancer antigen 125; HR, hazard ratio; 95\% CI, 95\% confidence interval.

Bold values indicate $P<0.05$.

analysis showed that endometriosis remained as an independent indicator of PFS (HR 0.054, $P=0.004$ ) and OS (HR 0.064, $P=0.007$ ).

\section{Construction and validation of prognostic nomogram for PFS and OS}

Significant prognostic factors were concluded from multivariate Cox regression analysis of PFS and
OS to establish nomogram (Figure 4). The nomogram illustrated FIGO stage as sharing the largest contribution to prognosis, followed by endometriosis and CA125. The calibration plot for the nomogram presented an optimal agreement between the predicted and actual observation for the PFS and OS at 5-year (Figure 5). 
A Nomogram for multivariable Cox model for PFS

Points

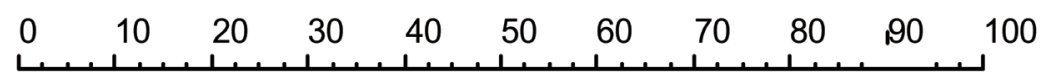

FIGO stage

CA125

Endometriosis

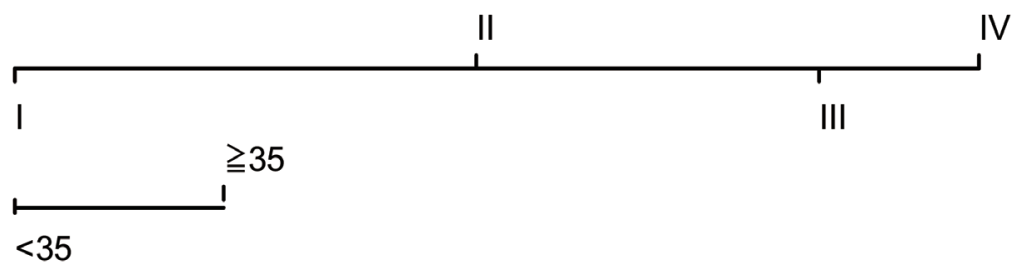

$<35$

Total Points

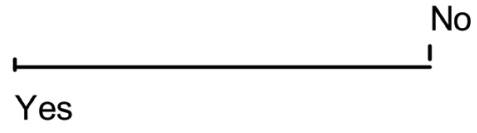

5-Year PFS Probability

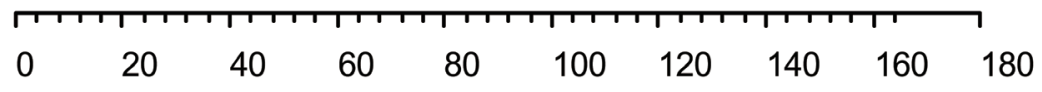

$\begin{array}{llllll}0.9 & 0.8 & 0.7 & 0.6 & 0.50 .40 .30 .2 & 0.1\end{array}$

B Nomogram for multivariable Cox model for OS

Points

FIGO stage

CA125

Endometriosis

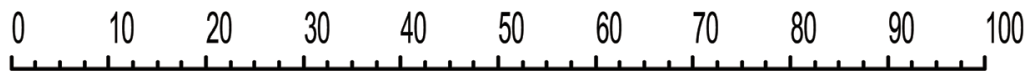

Total Points
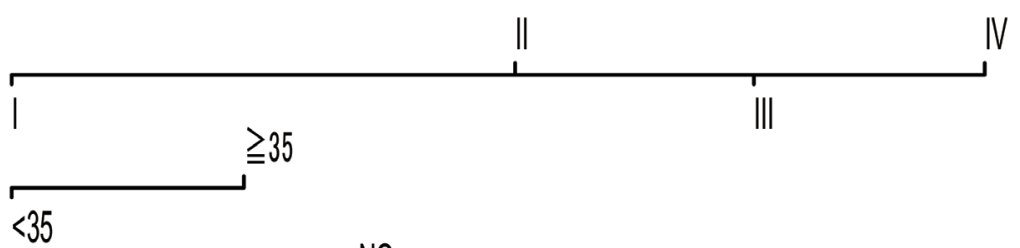

$<35$

NO

YES

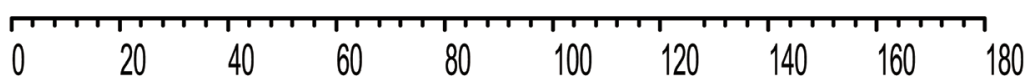

5-Year OS Probability

\begin{tabular}{llllllllll}
\hline 0.9 & 0.8 & 0.7 & 0.6 & 0.5 & 0.4 & 0.3 & 0.2 & 0.1
\end{tabular}

Figure 4: Survival nonograms. Nomograms were created from the multivariable Cox model. The presence or absence of each variable is scored (top row). The cumulative score from each variable is used to calculate 5-year PFS A. and OS B. probabilities. PFS $=$ progressionfree survival. OS $=$ overall survival. 
Table 3: Univariate and multivariate Cox regression analysis for progression-free survival (PFS) and overall survival (OS) of ovarian cancer patients with FIGO stage (I/II) according to various clinic-pathologic factors (n=143).

\begin{tabular}{|c|c|c|c|c|}
\hline \multirow{2}{*}{ Clinical variables } & \multicolumn{2}{|l|}{ PFS } & \multicolumn{2}{|l|}{ OS } \\
\hline & HR (95\%CI) & $P$ value & HR $(95 \%$ CI $)$ & $P$ value \\
\hline \multicolumn{5}{|l|}{ Univariate analysis } \\
\hline Age & $1.009(0.971-1.049)$ & 0.643 & $1.024(0.982-1.067)$ & 0.273 \\
\hline $\begin{array}{l}\text { Histology } \\
\text { clear cell } \\
\text { Endometrioid } \\
\text { Mixed }\end{array}$ & $\begin{array}{l}\text { Reference } \\
1.525(0.701-3.317) \\
3.891(1.315-11.511)\end{array}$ & $\begin{array}{l}0.085 \\
0.290 \\
\mathbf{0 . 0 1 5}\end{array}$ & $\begin{array}{l}\text { Reference } \\
1.252(0.538-2.915) \\
3.577(1.202-10.646)\end{array}$ & $\begin{array}{l}0.136 \\
0.604 \\
\mathbf{0 . 0 2 3}\end{array}$ \\
\hline $\begin{array}{l}\text { ECOG performance } \\
0-1 \\
2-3\end{array}$ & $\begin{array}{l}\text { Reference } \\
2.370(0.828-6.785)\end{array}$ & 0.110 & $\begin{array}{l}\text { Reference } \\
1.222(0.290-5.154)\end{array}$ & 0.786 \\
\hline $\begin{array}{l}\text { Intraperitoneal metastasis } \\
\text { negative } \\
\text { positive }\end{array}$ & $\begin{array}{l}\text { Reference } \\
4.938(2.171-11.234)\end{array}$ & $<0.001$ & $\begin{array}{l}\text { Reference } \\
4.710(1.960-11.320)\end{array}$ & $<0.001$ \\
\hline $\begin{array}{l}\text { Residual tumor }(\mathrm{cm}) \\
\leq 1 \\
>1\end{array}$ & $\begin{array}{l}\text { Reference } \\
5.092(1.215-21.341)\end{array}$ & 0.027 & $\begin{array}{l}\text { Reference } \\
5.494(1.301-23.196)\end{array}$ & 0.021 \\
\hline $\begin{array}{l}\text { Preoperative ascites }(\mathrm{ml}) \\
<500 \\
\geq 500\end{array}$ & $\begin{array}{l}\text { Reference } \\
1.942(0.681-5.538)\end{array}$ & 0.217 & $\begin{array}{l}\text { Reference } \\
1.480(0.448-4.895)\end{array}$ & 0.522 \\
\hline $\begin{array}{l}\text { Preoperative CA125 (U/ml) } \\
<35 \\
\geq 35\end{array}$ & $\begin{array}{l}\text { Reference } \\
1.813(0.890-3.694)\end{array}$ & 0.103 & $\begin{array}{l}\text { Reference } \\
1.825(0.864-3.853)\end{array}$ & 0.117 \\
\hline $\begin{array}{l}\text { Endometriosis } \\
\text { negative } \\
\text { positive }\end{array}$ & $\begin{array}{l}\text { Reference } \\
0.054(0.007-0.395)\end{array}$ & 0.004 & $\begin{array}{l}\text { Reference } \\
0.062(0.009-0.455)\end{array}$ & 0.007 \\
\hline \multicolumn{5}{|l|}{ Multivariate analysis } \\
\hline $\begin{array}{l}\text { Intraperitoneal metastasis } \\
\text { negative } \\
\text { positive }\end{array}$ & $\begin{array}{l}\text { Reference } \\
5.049(2.213-11.517)\end{array}$ & $<0.001$ & $\begin{array}{l}\text { Reference } \\
4.566(1.899-10.976)\end{array}$ & $<0.001$ \\
\hline $\begin{array}{l}\text { Endometriosis } \\
\text { negative } \\
\text { positive }\end{array}$ & $\begin{array}{l}\text { Reference } \\
0.054(0.007-0.391)\end{array}$ & 0.004 & $\begin{array}{l}\text { Reference } \\
0.064(0.009-0.462)\end{array}$ & 0.007 \\
\hline
\end{tabular}

Abbreviations: ECOG, Eastern Cooperative Oncology Group; FIGO, International federation of gynecology and obstetrics; CA125, cancer antigen 125; HR, hazard ratio; $95 \%$ CI, 95\% confidence interval.

Bold values indicate $P<0.05$.

A

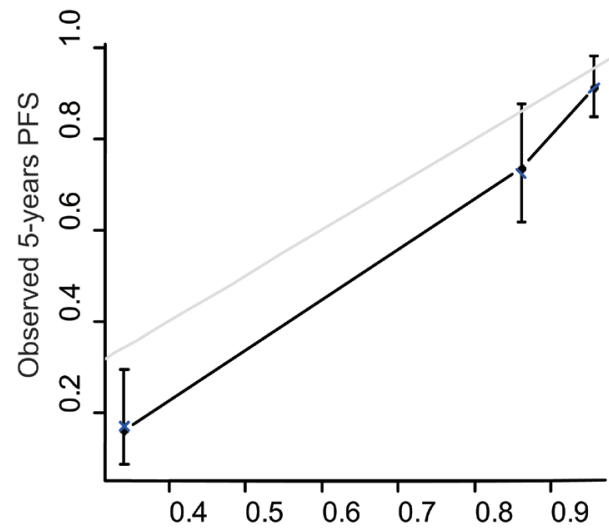

Nomogram predicted 5-years PFS
B

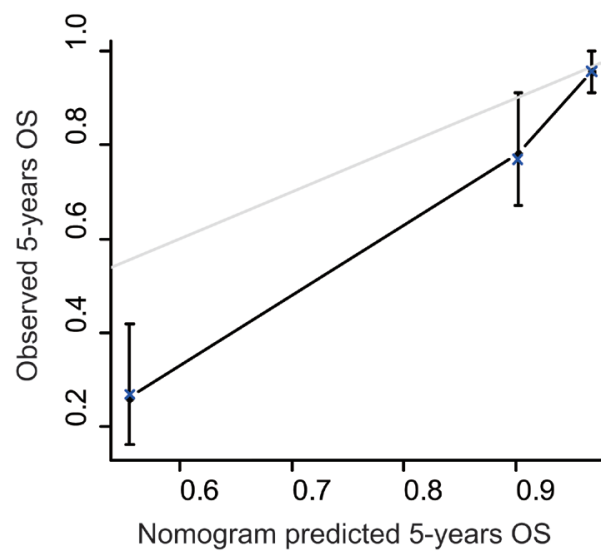

Figure 5: The calibration curves for predicting patient survival at each time point. Nomogram-predicted 5-year PFS A. and 5-year OS B. is plotted on the X-axis; actual PFS and OS is plotted on the y-axis. A plot along the 45-degree line would indicate a perfect calibration model in which the predicted probabilities are identical to the actual outcomes. 


\section{DISCUSSION}

Our study reported endometriosis as an independent predictor for PFS and OS in patients with ovarian cancer. Moreover, endometriosis manifests a discriminative power in early stage ovarian cancer subgroups, which can help guiding management of patients with early FIGO stage. The nomogram integrating endometriosis, FIGO stage and CA125 predicts 5-year PFS and OS well for ovarian cancer patients.

Ryu et al. explored most of the patients had diagnosed at an early stage (stage I, 61.3\%), and the overall 5-year survival rate was $57 \%$ [12]. Consistently, in our cohort, $121(61.7 \%)$ out of all patients was diagnosed at FIGO stage I, and the overall 5-year survival rate was $69.5 \%$. Moreover, we found that the overall 5-year survival rate was $91.5 \%$ in stage I, $56.3 \%$ in stage II, $26.4 \%$ in stage III, and $0 \%$ in stage IV (Supplementary Figure 1), which is quite consistent with data from the United states [13]. However, our study demonstrated that patients of ovarian cancer arising from endometriosis had a better prognosis, with $86.6 \%$ 5-year survival compared with $62.4 \%$ in patients of ovarian cancer without endometriosis, which was consistent with Shuang et al. [14].

The criteria for the definition of endometriosis associated ovarian cancer varied between different studies. Some authors considered the tumors as EAOC on the basis of malignant transformation in the endometriosis glands leading to carcinoma [10], whereas others included cases if either the transition point was identified or merely in the setting of any endometriosis was found within the surgical specimen coexisting with cancer [15]. We adopted the strictly histologic criteria for the diagnosis of ovarian cancer arising in endometriosis [16]. Additionally, the use of CD10 immunohistochemistry confirmed the diagnoses of ovarian cancer arising from endometriosis [17].

In our data, when FIGO stage was controlled, endometriosis remains significant on multivariate analysis between subjects and controls. This supports the hypothesis that EAOC as a distinct disease from non-EAOC with better prognosis [18]. ARID1A (ATrich interactive domain $1 \mathrm{~A}$ ) mutations and consequent loss of BAF250a (BRG-associated factor 250a) protein expression were particularly identified in EAOC, and in the contiguous atypical endometriotic lesions, but not in distinct endometrioid lesions far from the carcinoma, suggesting such phenomenon as a possible early event in the malignant transformation of endometriosis [19, 20]. ARIDIA mutations induce chromatin remodeling dysfunction and tend to coexist with activating PIK3CA mutations [21]. Moreover, atypical endometriosis and EAOC may share several molecular alterations such as ARID1A and PIK3CA mutations, PTEN loss, MET amplifications, and HNF1B overexpression, suggesting a common molecular mechanism for malignant development [22-24]. In an Apc- and Pten-defective mouse ovarian cancer model loss of ARIDIA enhances epithelial differentiation and prolongs survival, which may account for the better prognosis of ovarian cancer arising in endometriosis [25]. The clinical significance of loss of ARIDIA in EAOC has remained to be elucidated.

Our data are consistent with that of Shuang et al [14], who reported that $78.5 \%$ of clear cell cancer associated with endometriosis presented as stage I and II compared with $37.4 \%$ of clear cell ovarian cancers that are not associated with endometriosis. With regard to endometriosis as independent predictor for prognosis, there was a discrepancy between the study of Shuang et al [14] and our own. Resolving this issue only be these two studies is difficult because the number of patients in both studies was insufficient. Potential limitation of this analysis should be considered. This is a retrospective analysis, and data were obtained by clinical records; thus, only hard information, such as age and stage of the disease, were collected.

In conclusion, our study revealed that endometriosis is associated with better clinical outcomes in ovarian cancer patients. A prognostic model integrating endometriosis, FIGO stage and CA125 may improve the management of ovarian cancer patients in terms of risk stratification, individualizing postsurgical follow-up.

\section{MATERIALS AND METHODS}

\section{Patients}

After approval from institutional review board, we retrospectively identified 196 cases with a primary diagnosis of pure clear cell, endometrioid, or mixed ovarian cancer at our hospital between 1995 and 2010. Of the mixed tumors, 8 cases showed clear cell histology with endometrioid histology, whereas the remaining tumors showed heterogeneous histology consisting of endometrioid, clear cell, and serous differentiation. All patients underwent surgery according to Federation of Gynecology and Obstetrics (FIGO) guidelines for ovarian cancer. All patients received a platinum-based chemotherapy regimen, and the number of cycles ranged from six to nine after tailoring to different individuals. Microscopic slides were reviewed and confirmed by two experienced gynecologic pathologist (Dr. XT and JZ). Patients were divided into two groups according to the detection of cancer arising from ovarian endometriosis or not on the basis of the Sampson and Scott criteria: 1) the presence of both benign and neoplastic endometrial tissues in the tumor, 2) histological findings compatible with an endometrial origin, 3) the discovery of no other primary tumor sites, and 4) a morphologic demonstration of a continuum between benign and malignant epithelium [10]. Patients with the pathological findings confirmed 
endometriosis in close proximity to the tumor, but not histologically contiguous to the ovarian cancer tissue were excluded. The inclusion and exclusion criteria were summarized in Supplementary Figure 2. No statistically significant differences in tumor characteristics or survival outcomes were observed for included and excluded patients (Supplementary Table 2 and Supplementary Figure 3).

\section{Immunohistochemistry}

The primary formalin-fixed, paraffin-embedded ovarian cancer tissues arising from endometriosis were applied with CD10 immunohistochemical staining. Immunohistochemistry protocol was described previously [26]. The primary antibody against human CD10 (clone 56C6, DAKO; dilution: 1: 200) was applied in the procedure. Positive staining was subjectively classified as weak, moderate, or strong.

\section{Statistical analysis}

Correlations between endometriosis and clinicopathologic characteristics were analyzed with $\chi^{2}$ test. Clinical outcomes were assessed by progression free survival (PFS) and overall survival (OS). PFS was defined as the interval between the date of surgery and the date of diagnosis of any type of progression. OS was defined as the interval between surgery and death. Patients were censored if they were lost to follow-up or if they show not progression or were still alive at the time of last followup. Follow up was updated in Feb 2015. Kaplan-Meier method with log-rank test was applied to compare survival curves. Univariate and multivariate Cox regression models were fitted to evaluate the effect of prognostic factors on OS and PFS, and $P>0.10$ was the removal criterion when performing backward stepwise variable deletions. Nomogram was constructed as the prognostic model whose accuracy was evaluated by the Calibration plot. Data were analyzed using MedCalc software (version 12.7.0.0; MedCalc, Mariakerke, Belgium), and R software, version 3.1.2 (The R Foundation for Statistical Computing, http://www.r-project.org). All statistical tests were two sided and performed at a significance level of 0.05 .

\section{CONFLICTS OF INTEREST}

The authors declare no competing interests.

\section{GRANT SUPPORT}

This study was supported by grants from National Natural Science Foundation of China (31570803, 81272879, 81402151), Research Program of Shanghai
Municipal Commission of Health and Family Planning (20154Y0049).

\section{REFERENCES}

1. Jayson GC, Kohn EC, Kitchener HC and Ledermann JA. Ovarian cancer. Lancet. 2014; 384(9951):1376-1388.

2. Giudice LC. Clinical practice. Endometriosis. The New England journal of medicine. 2010; 362(25):2389-2398.

3. Brown J and Farquhar C. Endometriosis: an overview of Cochrane Reviews. The Cochrane database of systematic reviews. 2014; 3:CD009590.

4. Stewart LM, Holman CD, Aboagye-Sarfo P, Finn JC, Preen DB and Hart R. In vitro fertilization, endometriosis, nulliparity and ovarian cancer risk. Gynecologic oncology. 2013; 128(2):260-264.

5. Buis CC, van Leeuwen FE, Mooij TM and Burger CW. Increased risk for ovarian cancer and borderline ovarian tumours in subfertile women with endometriosis. Hum Reprod. 2013; 28(12):3358-3369.

6. Pearce CL, Templeman C, Rossing MA, Lee A, Near AM, Webb PM, Nagle CM, Doherty JA, Cushing-Haugen KL, Wicklund KG, Chang-Claude J, Hein R, Lurie G, Wilkens LR, Carney ME, Goodman MT, et al. Association between endometriosis and risk of histological subtypes of ovarian cancer: a pooled analysis of case-control studies. The Lancet Oncology. 2012; 13(4):385-394.

7. Deligdisch L, Penault-Llorca F, Schlosshauer P, Altchek A, Peiretti $\mathrm{M}$ and Nezhat F. Stage I ovarian carcinoma: different clinical pathologic patterns. Fertility and sterility. 2007; 88(4):906-910.

8. Melin A, Lundholm C, Malki N, Swahn ML, Sparen P and Bergqvist A. Endometriosis as a prognostic factor for cancer survival. International journal of cancer. 2011; 129(4):948-955

9. Wang S, Qiu L, Lang JH, Shen K, Huang HF, Pan LY, $\mathrm{Wu}$ M, Yang JX and Guo LN. Prognostic analysis of endometrioid epithelial ovarian cancer with or without endometriosis: a 12-year cohort study of Chinese patients. American journal of obstetrics and gynecology. 2013; 209(3):241 e241-249.

10. Kumar S, Munkarah A, Arabi H, Bandyopadhyay S, Semaan A, Hayek K, Garg G, Morris R and Ali-Fehmi R. Prognostic analysis of ovarian cancer associated with endometriosis. American journal of obstetrics and gynecology. 2011; 204(1):63 e61-67.

11. Davis M, Rauh-Hain JA, Andrade C, Boruta DM, 2nd, Schorge JO, Horowitz NS, May T and del Carmen MG. Comparison of clinical outcomes of patients with clear cell and endometrioid ovarian cancer associated with endometriosis to papillary serous carcinoma of the ovary. Gynecologic oncology. 2014; 132(3):760-766.

12. Ryu SY, Park SI, Nam BH, Kim I, Yoo CW, Nam JH, Lee $\mathrm{KH}$, Cho CH, Kim JH, Park SY, Kim BG and Kang SB. 
Prognostic significance of histological grade in clear-cell carcinoma of the ovary: a retrospective study of Korean Gynecologic Oncology Group. Annals of oncology. 2009; 20(6):1032-1036.

13. Chan JK, Teoh D, Hu JM, Shin JY, Osann K and Kapp DS. Do clear cell ovarian carcinomas have poorer prognosis compared to other epithelial cell types? A study of 1411 clear cell ovarian cancers. Gynecologic oncology. 2008; 109(3):370-376.

14. Ye S, Yang J, You Y, Cao D, Bai H, Lang J, Chen J and Shen K. Comparative study of ovarian clear cell carcinoma with and without endometriosis in People's Republic of China. Fertility and sterility. 2014; 102(6):1656-1662.

15. Orezzoli JP, Russell AH, Oliva E, Del Carmen MG, Eichhorn $\mathrm{J}$ and Fuller AF. Prognostic implication of endometriosis in clear cell carcinoma of the ovary. Gynecologic oncology. 2008; 110(3):336-344.

16. Scarfone G, Bergamini A, Noli S, Villa A, Cipriani S, Taccagni G, Vigano P, Candiani M, Parazzini F and Mangili G. Characteristics of clear cell ovarian cancer arising from endometriosis: a two center cohort study. Gynecologic oncology. 2014; 133(3):480-484.

17. Agarwal $\mathrm{N}$ and Subramanian A. Endometriosis morphology, clinical presentations and molecular pathology. Journal of laboratory physicians. 2010; 2(1):1-9.

18. Erzen M, Rakar S, Klancnik B and Syrjanen K. Endometriosis-associated ovarian carcinoma (EAOC): an entity distinct from other ovarian carcinomas as suggested by a nested case-control study. Gynecologic oncology. 2001; 83(1):100-108.

19. Wiegand KC, Shah SP, Al-Agha OM, Zhao Y, Tse K, Zeng T, Senz J, McConechy MK, Anglesio MS, Kalloger SE, Yang W, Heravi-Moussavi A, Giuliany R, Chow C, Fee $\mathrm{J}$, Zayed A, et al. ARID1A mutations in endometriosisassociated ovarian carcinomas. The New England journal of medicine. 2010; 363(16):1532-1543.
20. Maeda D, Mao TL, Fukayama M, Nakagawa S, Yano T, Taketani Y and Shih Ie M. Clinicopathological significance of loss of ARID1A immunoreactivity in ovarian clear cell carcinoma. International journal of molecular sciences. 2010; 11(12):5120-5128.

21. Jones S, Wang TL, Shih Ie M, Mao TL, Nakayama K, Roden R, Glas R, Slamon D, Diaz LA, Jr., Vogelstein B, Kinzler KW, Velculescu VE and Papadopoulos N. Frequent mutations of chromatin remodeling gene ARID1A in ovarian clear cell carcinoma. Science. 2010; 330(6001):228231.

22. Sato N, Tsunoda H, Nishida M, Morishita Y, Takimoto $\mathrm{Y}$, Kubo T and Noguchi M. Loss of heterozygosity on 10q23.3 and mutation of the tumor suppressor gene PTEN in benign endometrial cyst of the ovary: possible sequence progression from benign endometrial cyst to endometrioid carcinoma and clear cell carcinoma of the ovary. Cancer research. 2000; 60(24):7052-7056.

23. Gadducci A, Lanfredini $\mathrm{N}$ and Tana R. Novel insights on the malignant transformation of endometriosis into ovarian carcinoma. Gynecological endocrinology. 2014; 30(9):612617.

24. Yamashita Y. Ovarian cancer: new developments in clear cell carcinoma and hopes for targeted therapy. Japanese journal of clinical oncology. 2015; 45(5):405-407.

25. Zhai Y, Kuick R, Tipton C, Wu R, Sessine M, Wang Z, Baker SJ, Fearon ER and Cho KR. Aridla inactivation in an Apc- and Pten-defective mouse ovarian cancer model enhances epithelial differentiation and prolongs survival. The Journal of pathology. 2016; 238(1):21-30.

26. Potlog-Nahari C, Feldman AL, Stratton P, Koziol DE, Segars J, Merino MJ and Nieman LK. CD10 immunohistochemical staining enhances the histological detection of endometriosis. Fertility and sterility. 2004; 82(1):86-92. 